\title{
OPPORTUNITIES AND PRIORITIES IN A NEW ERA FOR WEATHER AND CLIMATE SERVICES
}

\author{
BY JOHN A. DUTTON
}

\section{Expanding capabilities and new requirements for atmospheric information services create an} exciting new era with economic and political challenges and a need for clear priorities.

$R$ apid change is sweeping through atmospheric science and services in response to new scientific opportunities and new demands for atmospheric information. The scientific opportunities arise from advances in observing and predicting atmospheric events and from rapidly developing computer and communications capabilities. At the same time, new information is required as the management of weather risk expands from protection of life and property to reduction of profit volatility in weather-sensitive industries.

These two dimensions of dramatic changeadvancing scientific skill coupled with more sophisticated management of weather and climate risk-are largely a consequence of rapidly expanding capability for managing and communicating complex streams of data and information. Indeed, the opportunities and demands merge as atmospheric observations and predictions are combined with business data in corporate computer databases and models.

AfFILIATION: DUTtON-The Pennsylvania State University, University Park, Pennsylvania and Weather Ventures Ltd, Boalsburg, Pennsylvania CORRESPONDING AUTHOR: Dr. John A. Dutton, College of Earth and Mineral Sciences, The Pennsylvania State University, II6 Deike Building, University Park, PA 16802

E-mail: dutton@ems.psu.edu

In final form 22 May 2002

C2002 American Meteorological Society
Reflecting these opportunities, three contemporary realities drive the evolution of weather and climate services.

- Timescales of interest are expanding toward both shorter and longer periods as efforts to manage weather and climate risk become more comprehensive and more quantitative. On the shorter timescales, energy is traded in fractions of hours in response to weather-induced demand; the agricultural and related industries, among others, use weather information to govern activities on the scale of hours. On the longer scales, monthly and seasonal forecasts facilitate the financial strategies now used to hedge weather risks in energy, retail, and other industries.

- Effective strategies for quantitative management of weather and climate-related risk depend increasingly on integrating atmospheric observations, statistics, and forecasts with the operational and financial models used to assess alternative actions, manage the business, and judge results. New probabilistic approaches to management of weather and climate risk require sophisticated and reliable information about climate and climate variability.

- Weather and climate services, both federal and private, are becoming more distributed (in the sense of more nodes in the network), more varied, and more widely available as a consequence of advanc- 
ing information technology and broader demand. And as in the open source computer community, wider distribution leads to enhanced creativity and advancing capability as a thousand flowers bloom.

Together these realities are shaping a new era in weather and climate services. Some of them were becoming clear a decade ago as Dutton (1992) reviewed some of the scientific and policy challenges then evident. The first American Meteorological Society (AMS) Presidential Policy Forum in January 2001 inquired whether realities of the day mandate new priorities or policies for the discipline. A number of recommendations were presented at the forum, including those recently published in the Bulletin by White (2001). As part of the forum, this essay argues, as did the National Research Council (NRC 1998), for the following two key recommendations.

- The top priority for improvement in weather and climate services is optimization and integration of the observation, modeling, and prediction system with a special focus on improved observations of water and other key variables.

- The weather and climate services partnership will be more effective in serving the nation and individual clients if the public, private, and academic sectors focus together and collaboratively on the priorities and resources that are critical for progress.

More recently, the NRC (2001) has produced a vision of enhanced climate services, including a list of guiding principles and a number of recommendations for "first steps" toward developing institutional capability to provide more effective climate information.

The new era in weather and climate services is a consequence of scientific and technological advance. But some of the most significant challenges of the new era are neither scientific nor technological-rather, they are economic and political, they involve federal priorities, and they mandate and require cooperation among all members of the weather and climate community. Moreover, it seems quite evident that those who depend on weather and climate services to manage substantial weather and climate risk should be acting through the national political process to demand improved capabilities in atmospheric observation, prediction, and services.

\section{MANAGING WEATHER AND CLIMATE}

RISK. Weather and climate have favorable or adverse effects on an expanding range of activities. Some of these effects can be ameliorated with accurate forecasts and protective action. Others, like those owing to extreme climate variations, cannot be prevented, but often insurance or hedging strategies can reduce the financial impacts.

Today, there is a growing awareness of weather and climate effects on financial performance. Examples include the report by FirstEnergy that 2001 fourthquarter revenues from electricity sales in the northeastern United States were $\$ 122$ million less than the year before owing to mild winter weather. Another energy company, Dominion, reports an earnings decrease of 19 cents per share, or $\$ 47$ million, in the first quarter of 2002 owing to adverse weather conditions. The 2000 annual report for Friendly's restaurants said that "results for the year were negatively impacted" in part by "unusually cool weather in the northeast, especially in the summer months." A Met Office survey of British industry (Met Office 2001) found that $95 \%$ of the respondents admitted to losses of $10 \%$ of profits owing to adverse weather and climate effects. Nearly half said they could not prevent weather-related losses. (A wealth of comprehensive information on recent and historical impacts and costs of severe weather and climate events is available on the National Climatic Data Center's Web site.)

\begin{tabular}{|l|l|}
\hline \multicolumn{1}{|c|}{ TABLE I. Strategies for mitigating weather and climate risk. } \\
\hline \multicolumn{1}{|c|}{ Risk } & \multicolumn{1}{|c|}{ Strategies } \\
\hline Severe weather or weather events & $\begin{array}{l}\text { Avoidance through flight, by } \\
\text { taking refuge, or canceling } \\
\text { weather sensitive activities in } \\
\text { response to forecasts or } \\
\text { warnings; preparation, including } \\
\text { building codes; insurance }\end{array}$ \\
\hline Unusual seasonal variations & $\begin{array}{l}\text { Preparation, insurance, hedges of } \\
\text { risk through futures contracts on } \\
\text { commodities or through options } \\
\text { (called weather derivatives) with } \\
\text { payouts contingent on weather } \\
\text { variables }\end{array}$ \\
\hline Long-term climate variations & $\begin{array}{l}\text { Planning, reduction of sensitivity, } \\
\text { very long-term hedging contracts }\end{array}$ \\
\hline
\end{tabular}




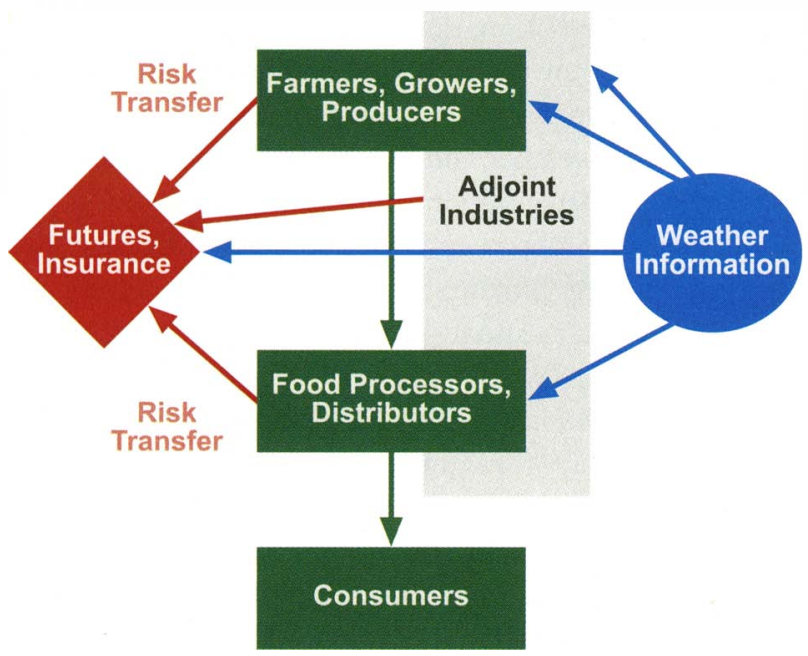

FIG. I. Flows of agricultural products, weather information, and transfers of financial risk.

Definition of weather and climate risk. For the present purposes, we define weather and climate risk as the possibility of injury, damage to property, or financial loss owing to severe or extreme weather events, unusual seasonal variations such as heat waves or droughts, or long-term changes in climate or climate variability. There are many definitions of risk in the insurance and financial worlds, but here it is advantageous to define the risk associated with an event or condition as

\section{Risk $=($ Probability of Occurrence $)($ Cost of the Consequences of Occurrence),}

which makes it clear that the role of weather and climate advisors is to provide those at risk with reliable estimates of the probability of occurrence of events ranging from severe weather to climate change. Table 1 summarizes some of the strategies for mitigating or coping with weather and climate risk. The weather derivatives in the middle of the right column are a new financial strategy that will be explained below.

Mitigation strategies. The agricultural industries have developed a focused and sophisticated system for integrating weather, climate, and risk information, as illustrated in Fig. 1. Weather and climate information is used directly in planning and managing crops and protecting against pests. In addition, the various risks faced by food producers and processors can be exchanged or hedged with insurance or commodity futures contracts. In the case of agriculture, futures contracts are traded extensively in markets that respond to weather events as well as to other forces acting on supply and demand. By limiting variability in returns or costs, these contracts provide both growers and processors with acceptable financial boundaries while creating the possibility that third parties who absorb the risk may achieve profit in return. The point for the atmospheric sciences community is that contemporary agriculture employs a wide variety of meteorological services related directly to food production and processing as well as to the markets in which the weather risks are hedged financially.

Transportation, public utilities, retail sales, recreation, and construction are also sensitive to weather and climate. These and other industries have developed various risk management strategies that require atmospheric information. A vibrant need for weather and climate services is developing in response to weather risk management in the energy industry, a need stimulated in part by the new economic environment created by deregulation. As an example, wintertime residential energy consumption is strongly dependent on temperature. Cold temperatures lead to greater consumption and presumably greater profit for energy producers and distributors; warm temperatures reduce sales and create the possibility of a financial loss that might be mitigated by an appropriate hedging strategy. The situation reverses in the summer, with warm temperatures being advantageous and cool temperatures leading to reduced income or financial losses for producers and distributors. Thus the energy industry is rapidly developing a system similar to that of agriculture for securing weather information and protecting against risk, as shown in Fig. 2.

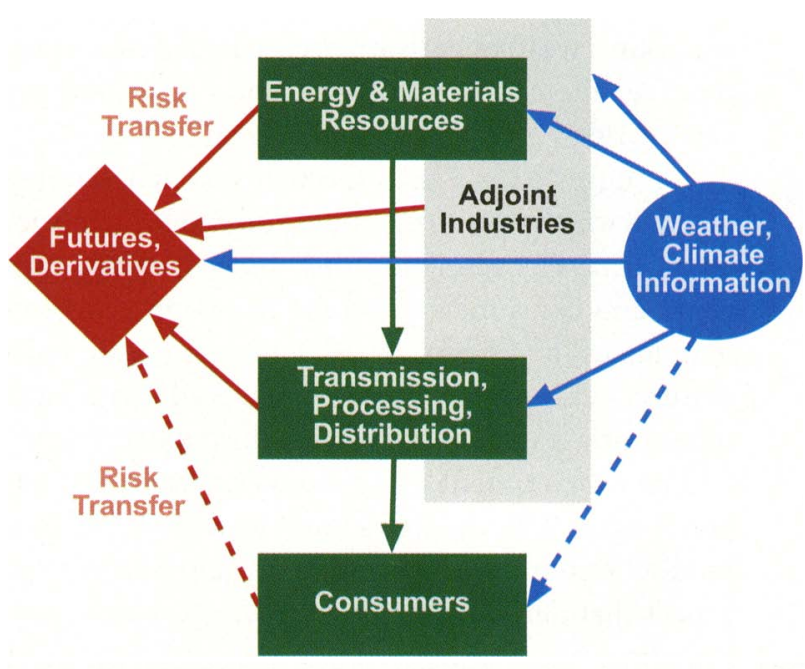

Fig. 2. Flows of resources, weather information, and financial risk in energy and some materials industries. 
Weather derivatives. A contract with a future settlement contingent on weather or climate variables is a relatively new financial instrument. In financial parlance, it is called a weather derivative because the value derives from a weather variable. Contracts can be written between parties in a wide variety of formats. A common one involves degree days as measures of climate variation. For example, a utility in a northern state might contract to receive $\$ 10,000$ for every degree day less than 7000 for the winter season, with a limit of $\$ 10$ million on the payout. The cost of such a contract might be in the range of $25 \%$ of the limit, but would be based more precisely on the expected variability of degree days at an appropriate weather station or stations, and thus the importance of accurate climatological information in the weather risk market becomes obvious. Moreover, the value of longterm probabilistic forecasts of seasonal deviations from normal conditions also becomes obvious. Various aspects of weather risk and weather derivatives are covered in the collection of articles in Dischel (2002), including one by Dutton (2002) on some meteorological aspects of weather risk management. For an example of how weather derivatives might be used in the energy industry, see Dischel (1999).

Weather derivatives represent somewhat esoteric financial contracts in which money changes hands based on seasonal average temperatures, degree days, or precipitation amounts. Most of the seasonal weather derivative contracts have involved over-thecounter agreements, but options based on temperature in selected cities trade on the Chicago Mercantile Exchange and the London International Financial Futures and Options Exchange. According to a survey sponsored by the Weather Risk Management Association (WRMA 2002), the total notional value of seasonal weather derivatives executed between parties over-the-counter has been about $\$ 2$ billion per year in 1998-2000 and $\$ 4$ billion in 2001 .

As suggested in Fig. 2, mechanisms may develop through which consumers could also hedge their price risk, perhaps by acting together. Indeed, energy suppliers and consumers generally have opposing meteorological and financial risk and could, as in agriculture, act on opposite sides of a trade with each other or by transferring risk to a third party.

The development of precipitation contracts has been impeded by the well-known spatial and temporal discontinuities in precipitation amounts. We can expect that derivatives based on wind statistics will soon be available, as both producers and purchasers of wind energy seek to mitigate weather and climate risk.
The weather risk market, as the trade in weather derivatives is known, has generated considerable interest in new approaches to management of the financial aspects of weather and climate risk. The market, especially its open components, has not developed as rapidly as some observers expected, in part because the firms hedging climate risk prefer contracts focused on their particular situation and hence deal directly with counterparties in private transactions. Thus the market has not yet developed the transparency and liquidity necessary for significant growth and for participation by third parties. Moreover, there is a cost involved in hedging, and the parties bearing the risk must be compensated, over the long run, for the losses they bear (Dutton 2002). The major advantage of weather derivatives for those at risk is that they can reduce the volatility of earnings dramatically, albeit at the cost of a long-term reduction in total return. For some, the predictability of earnings is very valuable, for others volatility is not as ominous.

Weather sensitive industries. The total opportunity for weather services in support of economically significant activities is illustrated in Table 2. The first two columns show the major categories of the gross domestic product and the federal estimate of their contribution to the gross domestic product (GDP). The third indicates those that (in the author's opinion) are, to some extent, sensitive to weather and climate events and variations. The conclusion is that some one-third of the private industry activities, representing annual revenues of some $\$ 3$ trillion, have some degree of weather and climate risk. This represents a large market for atmospheric information, and it should represent a powerful force for advancing the cause of atmospheric observation and prediction.

\section{FORECAST SKILL, RISK, AND OPPORTU-}

NITIES. The timescales of meteorological forecasts have expanded in recent years as the reliability for periods of one to three days steadily increased. Satellite imagery and the Weather Surveillance Radar1988 Doppler (WSR-88D) and other radar systems have provided a significant increase in shorter-term information and in warnings of severe weather. Increased computational power, improved observations, especially of sea surface temperature, and the advantages of ensemble forecasts have stimulated experiments with operational prediction of average conditions from a week to a season in advance. The $\mathrm{Na}$ tional Centers for Environmental Prediction report a wide variety of verification data on their Internet sites, and summaries show that 72 -h operational fore- 
TABLE 2. Weather and climate sensitive components of the gross domestic product (GDP; \$ billion). The first two columns are from the Bureau of Economic Analysis industry accounts data for 2000; the third column lists the contribution to the GDP of industries with a (subjectively determined) weather sensitivity on operations, demand, or price.

\section{Industries \\ (1987 standard industrial classification)}

Agriculture, forestry, and fishing

Farms

Agricultural services, forestry, and fishing

Mining

Coal mining

Oil and gas extraction

Other mining

\section{Construction}

Manufacturing

Transportation and public utilities

Transportation

Railroad transportation

Local and interurban passenger transit

Trucking and warehousing

Water transportation

Transportation by air

Other transportation

Communications

Electric, gas, and sanitary services

Wholesale trade

Retail trade

Finance, insurance, and real estate

Security and commodity brokers

Insurance carriers

Insurance agents, brokers, and service

Other finance, insurance, real estate

\section{Services}

Hotels and other lodging places

Auto repair, services, and parking

Amusement and recreation services

All other services

\section{Statistical discrepancy}

TOTAL FOR PRIVATE INDUSTRY

Federal government

State and local government
GDP components (\$ billion)

Weather sensitive components (\$ billion)
135.8

79.0

56.7

56.7

| $27 . \mid$

10.1

109.6

10.1

99.5

17.5

0.0

463.6

463.6

I,566.6

825.0

786.5

22.9

22.9

18.7

126.0

126.0

14.8

93.0

0.0

28I.I

230.0

230.0

674.

893.9

893.9

I,936.2

379. I

144.2

I 44.2

167.7

167.7

67.3

67.3

I,557. I

2,164.6

261.2

86.5

86.5

93.9

93.9

80.8

80.8

I,903.4

$-130.4$

$8,656.5$

387.0

829.5

829.5

$9,872.9$ 


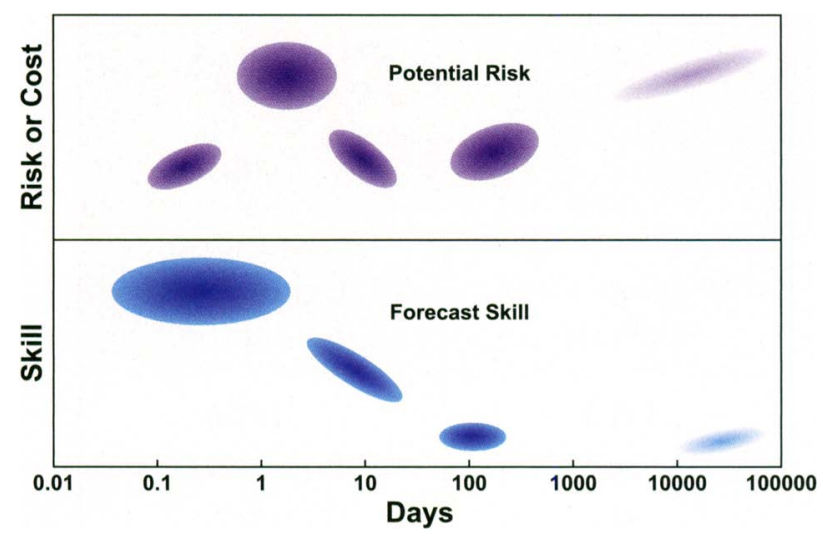

Fıg. 3. Subjective assessment of forecast skill and potential risk over a wide range of forecast periods.

casts at $500 \mathrm{mb}$ are now as accurate as 36 -h forecasts were some 20 years ago.

"How good are the forecasts?" is a question frequently encountered by all meteorologists. A subjective assessment of forecast skill over a wide range of forecast periods is shown in the lower half of Fig. 3. The precise meaning of "skill" is intentionally not specified, and the axis is intentionally not labeled with quantitative values, but as expected, skill declines as the forecast period increases from days to months. The gray ellipse on the lower right is intended to suggest skill associated with climate statistics and the simulation of forced global change.

Weather risk related to life and property and to financial loss presumably peaks at periods of one to three days with severe weather events such as hurricanes or major winter storms, as shown in the upper panel of Fig. 3, which gives a subjective assessment of potential risk by forecast period.

As determined by the opportunity for reduction of risk, improved analysis, prediction, and visualization at periods of 2 or 3 to $12 \mathrm{~h}$ would be advantageous to diverse activities, including aviation, electrical energy generation and trading, agricultural pest control, and construction. Improving skill at periods on the order of 10 days will permit longer-range planning for a variety of activities. And the linking of reliable probabilistic seasonal climate forecasts with quantitative risk management models and strategies will be advantageous in a wide range of economic endeavors. Dutton and Dischel (2001) compare and contrast the processes involved in weather and climate prediction.

The mechanisms of forecast preparation and delivery are changing significantly as both producers and users of weather and climate services turn increasingly to computer-based prediction, analysis, and communication. Figure 4 compares the traditional approach for incorporating weather information in decision making and the emerging approach in which four-dimensional fields of the standard meteorological variables, as predicted by federal forecast centers, are first converted by private sector firms into impact variables and decision aids specific to an industry and then finally incorporated numerically into the decision processes of individual enterprises (NRC 1994, 1998). As a specific example, the Climate Prediction Center releases a version of its seasonal forecasts as probability distributions of degree days in files that can be downloaded and used in financial markets to set prices for derivative contracts.

There are a number of important implications of this scenario.

- The federal forecast centers and the private sector groups computing impact variables will be more tightly linked and must cooperate as partners in a joint venture.

- Meteorologists will be more intimately involved in designing the decision process and less in forecasting the weather.

- Education for success in professional meteorology will require an entirely new dimension related to business and financial motivations, methods, and modeling.

- The opportunities for weather and climate information firms to work with clients are expanding as attention turns to information tailored to specific businesses.

The sources of atmospheric information are also changing rapidly. Today the major national forecast centers assimilate on the order of 10 million upperair observations per day in the computer prediction models, the bulk of them obviously from satellites. By 2010 , the data assimilation rate is expected to increase by five orders of magnitude as more satellite systems become operational, according to the Joint Center for Satellite Data Assimilation, an interagency planning effort (L. Uccellini 2001, personal communication).

Thus we can anticipate more detailed observation of atmospheric phenomena, higher-resolution predictions, and more accurate forecasts as the observational and computational technology and the scientific capabilities advance in parallel. The pathway to significantly improved seasonal climate anomaly predictions is not as obvious, but advancing computational capability will presumably allow extensive experimentation with larger and more varied ensembles and the development of models that will resolve the daily to 




Fıg. 4. Comparison of the classical and emerging forecast-decision models.

seasonal interactions between atmosphere, ocean, and land surface with increasing statistical fidelity.

New data sources and the tighter integration of atmospheric observation and prediction with the decision models of our constituents will produce a significant expansion in the impact and importance of atmospheric information. As strategies for managing the physical and financial aspects of weather and climate risk become more sophisticated and more widely used, we can expect the atmospheric sciences to have an increasing involvement in the planning and operations of both private and public ventures.

\section{PRIORITIES AND POLICIES FOR}

PROGRESS. The opportunities at this beginning of a new era in atmospheric science and services are evident and appealing, but lead us to ask what we must do to use them in assisting our constituents to manage weather and climate risk more effectively. These are the key strategic and policy questions for the discipline, our clients, and our governments-the answers should lead to the priorities for the atmospheric sciences and services.

These priorities will involve improving observations and models, maintaining the flow of data and analyses, and ensuring meaningful interagency cooperation; they will focus on stimulating effective public and private sector cooperation in developing services. Finally, the priorities will involve developing and presenting convincing arguments that funding based on progress, opportunity, and impact will be a wise national investment. White (2001) makes several important proposals for advancing and implementing such arguments.

In the United States, priorities related to weather and climate services must be formulated within the context of a complex partnership (NRC 1988), as illustrated in Fig. 5, in which

- the government obtains and analyzes observations and issues atmospheric data, forecasts, and warnings;

- private sector firms use government data and products as a basis for creating information and special products for the media and clients;

- the government and communication media disseminate atmospheric information, forecasts, and warnings to the public while tailored products move through information networks or dedicated channels; and

- scientists in the academic community, the government, and the private sector advance atmospheric understanding and assist in creating new capabilities for service.

Advancing rapidly in capability and sophistication in recent decades, the partnership has served the nation well. The national benefits from weather and climate information (NRC 1998) include protecting life and property, enhancing economic vitality, maintaining environmental quality, strengthening fundamental understanding, and contributing to national security. Today, it is recognized that these benefit can be enhanced by collaboration among the partners. Toward this end, the Atmospheric Policy Program of the American Meteorological Society is sponsoring a series of workshops involving government, private, and academic participants and posting reports and recommendations on the AMS Web site. Similarly, the National Oceanic and Atmospheric Administration (NOAA), WRMA, and the Risk Prediction Ini-

\section{The Classical Forecast - Decision Model}

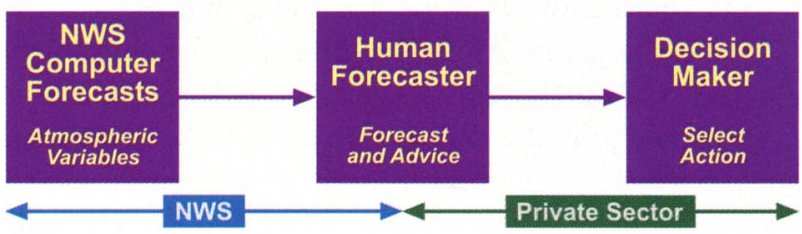

The New Era Forecast - Decision Model

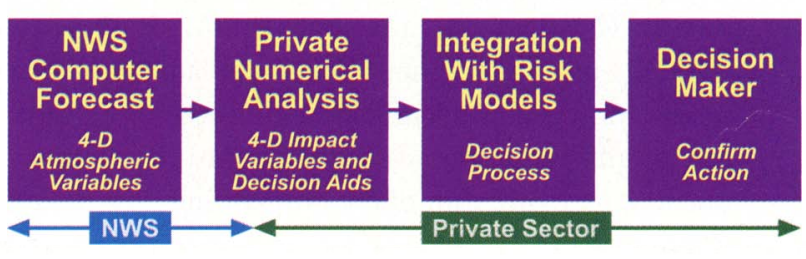

FIG. 5. The federal, private, and academic partnership in the atmospheric and climate sciences. 
tiative sponsored a workshop on the needs of the weather risk management industry in October 2001; a report is in preparation.

Further progress in atmospheric science and service will depend on the success with which we improve, optimize, and integrate observations and models of atmospheric, oceanic, and land surface processes, as emphasized by the NRC (1998). It will depend on the extent to which we take advantage of technology to obtain new observations on critical variables. It will depend on whether we maintain the free and open exchange of observed atmospheric dataworldwide.

The importance of atmospheric observations and the infrastructure required to obtain them cannot be overemphasized. The atmospheric science community recognizes that atmospheric observation is the foundation of the entire enterprise, as depicted in Fig. 6 . The users of weather and climate services should also realize that the services on which they depend are based on a complex, global network that, all too often, is taken for granted. Indeed, the United States' commitment to free and open exchange of data empowers the creativity of the academic and private sectors and stands in sharp and shining contrast to the situation in some nations in which meteorological data are severely restricted and sold commercially by the government.

Because improving, optimizing, and integrating observations, analysis, and models is the top priority, the atmospheric science community and the users of atmospheric information should insist together that the federal agencies involved in atmospheric science integrate their efforts and contribute in meaningful ways to a major national initiative to improve the atmospheric observation and modeling system. They should demand a visible and purposeful mechanism to coordinate atmospheric research and services and urge that the individuals involved be sufficiently highranking officials for the group to be effective and to be able to make and execute its own priorities and conclusions, in effect to override individual agency priorities in meeting higher national needs. The main players-NOAA, the National Aeronautics and Space Administration (NASA), the National Science Foundation (NSF), and the Department of Defense (DOD) - must strengthen efforts to create together an observation and modeling system tuned to the capabilities and requirements of the twenty-first century, one that takes account of the burgeoning flow of data from space, the increasing power of computers, and the benefits of design with the aid of rigorous numerical observing system simulation experiments.

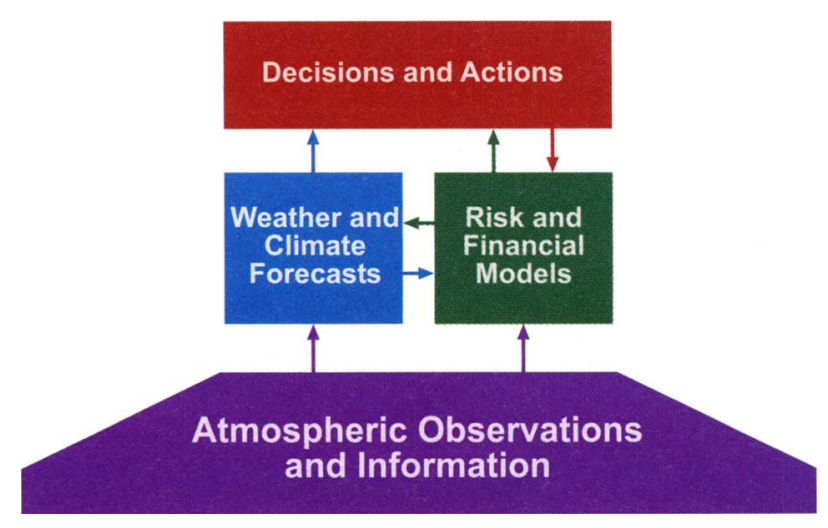

FIG. 6. Conceptual links between atmospheric observations, weather and climate models, and risk and financial models, and decisions and actions.

At the same time, the community of scientists and users, along with federal policy makers, needs to examine carefully whether the public, private, and academic components could collaborate in more promising ways as the atmospheric information system becomes more distributed, both conceptually and geographically. New capabilities, new opportunities for service, and the onrush of technology make it clear that there are important issues, some of which are examined by the NRC $(1998,49-50)$. Some argue that the federal government should be more vigorous in shaping national public and private capability to provide atmospheric services; others argue that market forces should determine the structure. Some argue that the high-quality, readily available federal information about weather and climate is the lifeblood of the private sector and that expanded federal services to taxpayers should be encouraged; others say that federal efforts should be constrained in order to provide opportunity to the private sector.

Finally (as always), resources are required. Both the public and private sectors of atmospheric science and the users should argue together for federal funding of the observations necessary to serve both public and private needs. And both groups should support the research on which advances are based and the education that provides talented professionals. Unfortunately, some of the recent discussion and activity has been divisive, with some groups seeking legislated restrictions on the activities of others. But the reality is that success in seeking individual advantage in the provision of weather and climate services would probably ensure loss of overall community capability and resources in the years ahead.

The argument for improved capability will be more compelling and the political pressure more powerful if atmospheric scientists and the users of 
weather and climate information unite to make the case together that further investment in atmospheric observations, science, and services will return remarkable dividends to the nation. Indeed, as indicated by Fig. 7, vigorous support from the private-sector users of weather and climate services could be a stroke of political lightning that stimulates the major national commitment required to optimize the observation network and more closely integrate observations and models.

Most of all, both the scientific community and the users of atmospheric information should take a longer view. For example, Gingrich (2000) argued that "a worldwide climatology project [including the] spacebased and land-based ocean and atmospheric [observation and] modeling that is technically possible with modern systems" should be a part of a federal "science budget for the next generation based on the opportunities in science. ..."

The atmospheric sciences community has a fairly clear vision of the opportunities for advances in understanding and service in the decades ahead. The challenge is to determine how we can-working together with the users of our services-optimize our

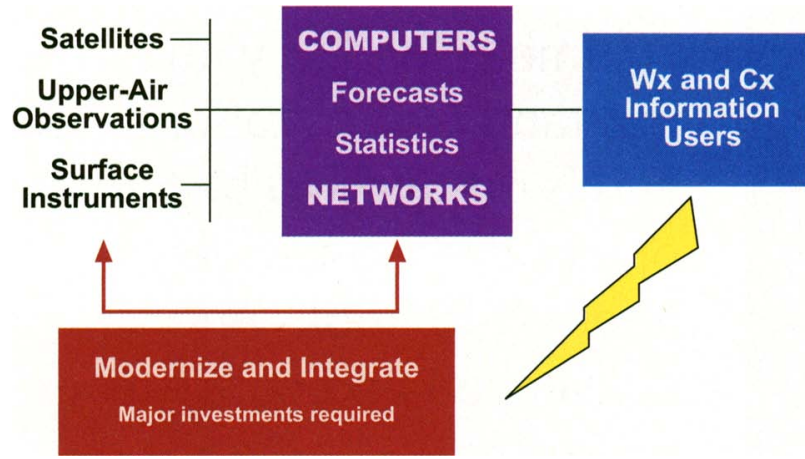

Fig. 7. Weather and climate information users should focus some of their political interest and priorities on supporting the federal investments required to modernize and integrate the observation and numerical forecast system. efforts and obtain the resources to realize those opportunities.

\section{REFERENCES}

Bureau of Economic Analysis, 2002: GDP by industry, www.bea.gov/bea/dn2/gpo.htm.

Dischel, R., 1999: Weather risk management at the Frozen Falls Fuel Company. Chicago Mercantile Exchange, 9 pp. [Available online at www.cme.com/ products/index/weather/products_index_weather_ riskmanagement.cfm.]

_- 2002: Climate Risk and the Weather Market: Financial Risk Management with Weather Hedges. Risk Books, 325 pp.

Dutton, J. A., 1992: The atmospheric sciences in the 1990s: Accomplishments, challenges, imperatives. Bull. Amer. Meteor. Soc., 73, 1549-1562.

—, 2002: The weather in weather risk. Climate Risk and the Weather Market: Financial Risk Management with Weather Hedges, R. S. Dischel, Ed., Risk Books, 185-211.

Dutton, J. F., and R. Dischel, 2001: Weather and climate predictions, minutes to months. Energy and Power Risk Management: Weather Risk Special Report, S30-S32.

Gingrich, N. 2000: An opportunities-based science budget. Science, 290, 1303.

Met Office, cited 2001: Companies not forecasting the hidden cost of weather. [Available online at www.met-office.gov.uk/corporate/pressoffice/ pr20011126.html.]

NRC, 1994: Weather for Those Who Fly. National Academy Press, 100 pp.

— 1998: The Atmospheric Sciences Entering the TwentyFirst Century. National Academy Press, 364 pp.

—, 2001: A Climate Services Vision: First Steps toward the Future. National Academy Press, 84 pp.

White, R. M., 2001: The evolving public-private meteorology partnership. Bull. Amer. Meteor. Soc., 82, 1431-1437.

WRMA, 2002: Second annual industry survey. www.wrma.org. 


\section{Metedrulggical Munggraph Na. 50}

Edited by Charles Doswell III

\section{Severe Convective Storms} Charles A. Doswell III, Editor

American Meteorological Society
This volume is a collection of 13 review papers by a distinguished group of scientists, providing a summary of the current scientific understanding of convective storms and the weather they produce, as well as showing how that understanding works in forecasting practice. The volume is loaded with outstanding illustrations, and is destined to become one of the most widely referred-to books on convection and convective processes.

\section{SEVERE CONVECTIVE STORMS, Meteorological Monograph No. 50}

ISBN 1-878220-41-1, 576 pp., hardbound, \$105 list/\$85 member, special student price: \$70. To place an order, submit your prepaid orders to: Order Department, AMS, 45 Beacon Street, Boston, MA 02108-3693; call 617-227-2425 to order by phone using Visa, Mastercard, or American Express; or send e-mail to amsorder@ametsoc.org. Please make checks payable to the American Meteorological Society. 